\title{
A study on the Development of Energy-Saving Device "Crown Duct"
}

\author{
Kwi-Joo Lee*, Jung-Sun An* and Sun-Hee Yang** \\ *Dept. of Naval Architecture \& Ocean Engineering, Chosun University, Gwangiu, Korea \\ **Basic Planning Department, SPP Shipbuilding Co., Ltd, Busan, Korea
}

KEY WORDS: Energy-saving device, Stator, Dual functioned energy saving device, Crown duct, Towing tank

ABSTRACT: A energy saving device "Crown duct" has been developed and its efficiency gain has been verified experimentally in the towing tank of SSPA. The preswirl stator is well known as one of energy saving devices, which recovering the rotational energy of propeller slipstream. Crown duct has two functions of recovers the rotational energy by three blades on top of duct and of flow concentration by semi-duct. The model tests showed 4.4\% efficiency gain with Crown Duct at full load condition and $6.9 \%$ at ballast condition compared with the bare hull ones for the middle class tanker.

\section{Introduction}

In the vicinity of a propeller, a pair of vortices is generated from the bilge at stern and give rise to viscous pressure resistance. Moreover, the stern flow generated from these vortices moves upward on both ship sides and moves downward near the center plane of the ship, leading to difference angle of attack of propeller blades on port and starboard side which may reduce the propeller efficiency.

Against the stern flow mechanism, the design of the stern fin generally plays a role as flow guiding device making a wake field near the upper part of the propeller plane uniform by both deflecting flow toward propeller and reducing the wake peak at propeller top position(Lee et al., 1992 and Lee et al., 1994).

pre-swirl stator consists of several fins which have almost the same span length as the propeller radius and are fixed radially on the stern frame in front of the propeller. Fig. 1 represents

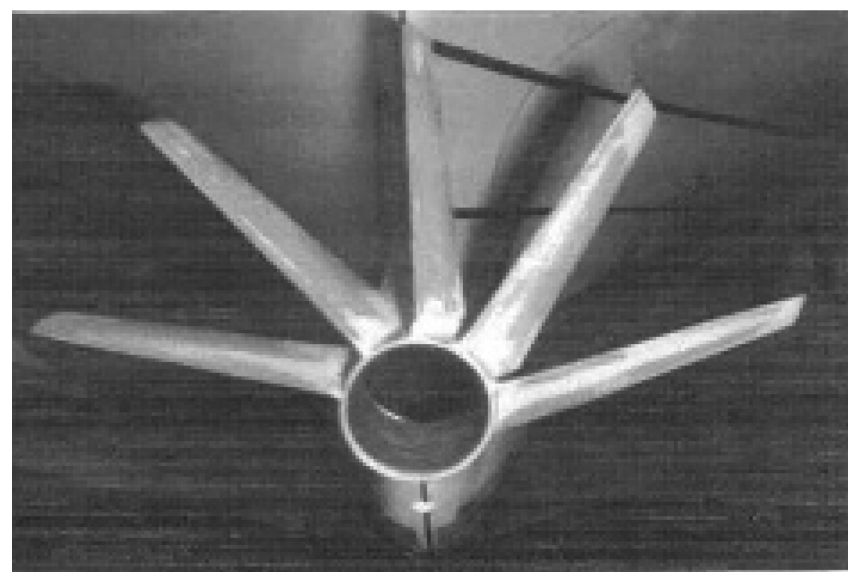

Fig. 1 Conventional preswirl fins an example of preswirl-stator. It is known that the wake factor (1-w) decreased considerably. This is caused by the fact that the reflecting flow was generated by the fins in front of the propeller plane. But high stress at the stand point of side fin in heaving and pitching motion, and non-negrigible added resistance due to this appendage are the problems should be solved (Asaumi et al., 2006 and Lee et al., 2012).

\section{Development of a New Type Energy-Saving Device "Crown Duct"}

The development of energy saving device having less added resistance and less stress on the stand point of side fins than conventional one, has been carried out by combination of semi-duct with minimum size of horizonal blades as to cut by half of the span length of the center fins. In case of full size horizontal fin, the setting angles were decided to control the flow near the fin tip. In this case, the fin is not effective to control properly the flow field near the fin root because of different inflow angle caused by hull induced longitudinal vortex, at the position of root, rather deteriorated the propulsive efficiency. Short length of side fin control the flow field only near the stern frame by which almost equal effect compare with the full size side fin. And small sized semi duct having diameter almost equal to about $50 \%$ of propeller diameter is attached to the tip of the short horizontal fin is designed to decrease the tip vortex(Lee et al.,2012; Lee and An, 2012) As shown in Fig. 2 and FIg. 3, this new energy-saving device consists of three fins on the stern frame and three plates on the duct.. This device has named "Crown duct", which enhance the safety for a drift

Corresponding author Jung Sun An: 309, Pilmun-daero, Dong-gu, Gwangju, Korea, +82-62-230-7882, running79@naver.com. 


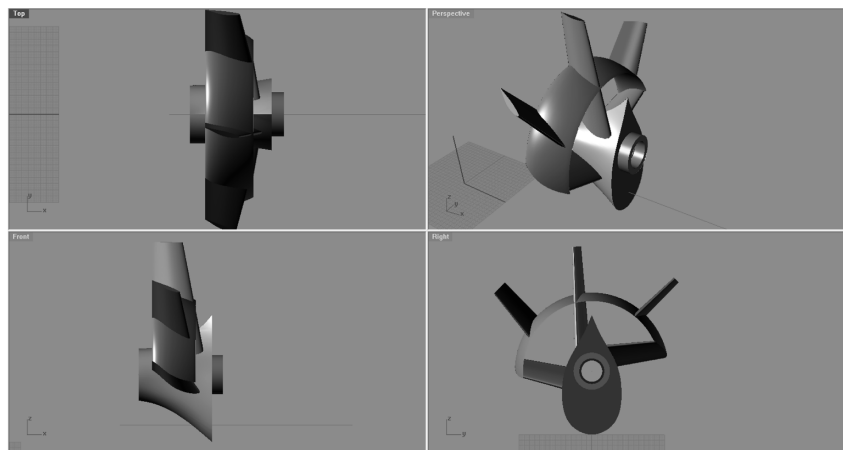

Fig. 2 3D configuration of crown duct

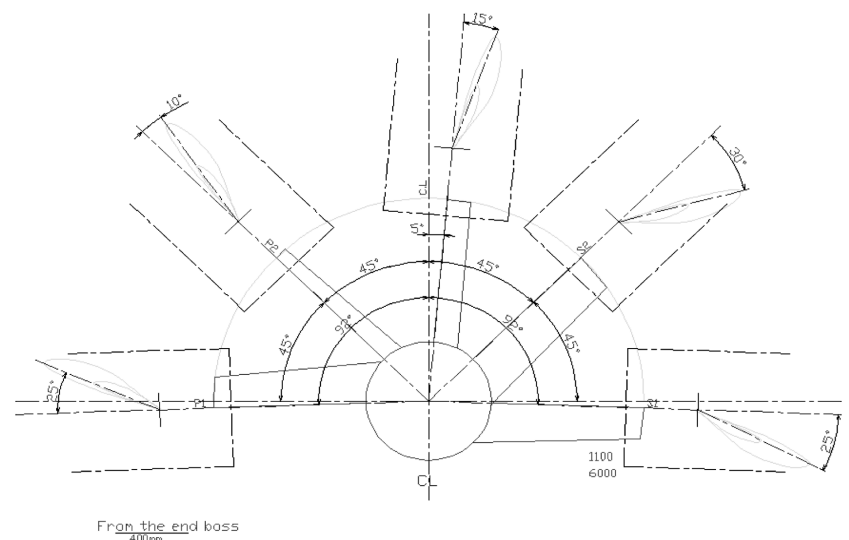

Fig. 3 Configuration of each stator

obstacle such as wood or timber, and simple structure leads to reduce manufacturing cost.

Crown duct is designed to reflect the stern vortices induced by the rotating propeller.

\section{Model Test}

Model tests are carried out in the towing tank of SSPA.

\subsection{Test facility}

The towing tank has the following main particulars:

- Length $260 \mathrm{~m}$

- Breadth $10 \mathrm{~m}$

- water depth $5 \mathrm{~m}$

- Maximum carriage speed $V_{\text {MAX }}=11 \mathrm{~m} / \mathrm{s}$

\subsection{Hull model}

- Ship model was manufactured in divinycell, a foam plastic material.

- The model scale is 1: 25.417

- The model has a turbulence trip wire at station 19. And the dimensions of full scale ship are as follews,

$L_{B P}=174 \mathrm{~m}$

$B=32.2 \mathrm{~m}$
$T=11.0 \mathrm{~m}$

\subsection{Propeller model}

The propeller model is a fixed, right turning, four bladed propeller with dimensions according to Table 1.

Table 1 Main particulars for model propeller

\begin{tabular}{cc}
\hline \hline Characteristic & Value \\
\hline Diameter model scale & $0.24 \mathrm{~m}$ \\
\hline Diameter full scale & $6.1 \mathrm{~m}$ \\
\hline Pitch ratio $P / D$ at $r / R=0.75$ & 0.715 \\
\hline Blade area ratio $A_{D} / A_{O}$ & 0.53 \\
\hline
\end{tabular}

3.4 Extrapolation by ITTC - 78 and Modified ITTC - 78

Without the crown duct mounted the predictions were made according to the 1978 ITTC extrapolation method.

With the crown duct mounted a somewhat modified wake scaling was used.

The method has been discussed within the 1999 ITTC and tentatively accepted for evaluation of pre-swirl stator concepts. The wake scaling presumes that tests with the same propeller but without the stator have been performed as well. The difference between model effective wake with stator and the model wake without stator is considered as a potential wake created by the stator.

The hull potential wake and the frictional wake are scaled as for the model with out stator according to the normal ITTC 78 method, to which the stator potential part is added. The amount 0.04 represents the potential wake created by the rudder at the location of the propeller.

Thus is in the modified ITTC 1978 extrapolation the full scale wake(Lare et al., 2011).

$$
\begin{aligned}
& W_{T s w}=\left(t_{w o}+0.04\right)+\left(W_{T m w o}-\left(t_{w o}+0.04\right)\right) \\
& *\left[(1+k) C_{F s}+\triangle C_{F s} /(1+k) C_{F m}\right]+\left[W_{T m w}-W_{T m w o}\right]
\end{aligned}
$$

where index

" $W$ " stands for "with crown duct"

"wo" stands for "without crown duct"

" $m$ " stands for "model"

"s" stands for "ship scale"

" $T$ " stands for "thrust identity"

The form factor is based on the case without crown duct.

\subsection{Result of model test}

The results of model tests are compared in Table 2 and Fig. 5 for full load condition and in Table 3 and Fig. 6 for ballast condition.

As shown in Table 2 and 3, new type of complex stator having less added resistance and less stress on the stand 


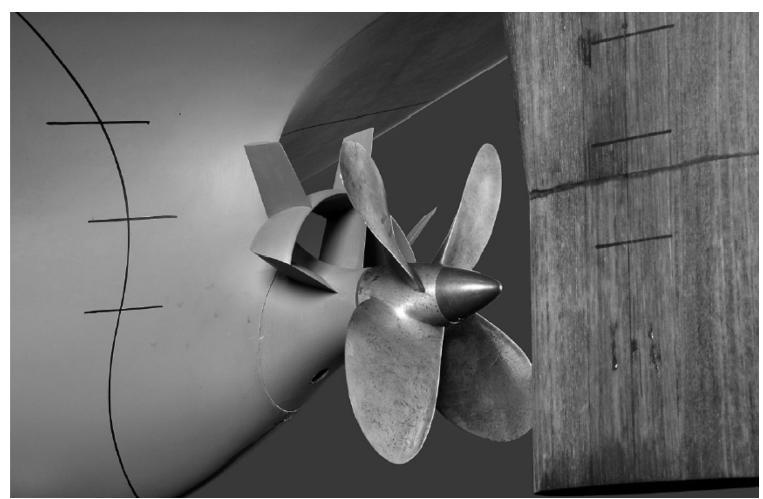

Fig. 4 Ship model with "Crown Duct"

Table 2 Model Test result in full load condition at design speed of 15.0 knot

\begin{tabular}{cccccccc}
\hline \hline Condition & $P_{E}(k W)$ & $w$ & $t$ & $\eta_{R}$ & $\eta_{O}$ & $\eta_{D}$ & $P_{D}(k W)$ \\
\hline Bare Hull & 4783 & 0.358 & 0.220 & 1.018 & 0.543 & 0.672 & 6740 \\
\hline $\begin{array}{c}\text { With Crown } \\
\text { Duct }\end{array}$ & 4792 & 0.453 & 0.247 & 1.031 & 0.494 & 0.701 & 6444 \\
\hline Diff. & $+0.19 \%$ & +0.095 & +0.027 & +0.013 & -0.049 & +0.029 & $-4.39 \%$ \\
\hline
\end{tabular}

Table 3 Model test result in ballast condition at the speed of 15.0 knots

\begin{tabular}{cccccccc}
\hline \hline condition & $P_{E}(k W)$ & $w$ & $t$ & $\eta_{R}$ & $\eta_{O}$ & $\eta_{D}$ & $P_{D}(k W)$ \\
\hline Bare Hull & 4256 & 0.399 & 0.215 & 1.014 & 0.541 & 0.717 & 5724 \\
$\begin{array}{c}\text { with Crown } \\
\text { Duct }\end{array}$ & 4243 & 0.490 & 0.233 & 1.030 & 0.493 & 0.764 & 5331 \\
Diff. & $-0.31 \%$ & +0.091 & +0.018 & +0.016 & -0.048 & +0.028 & $-6.87 \%$ \\
\hline
\end{tabular}

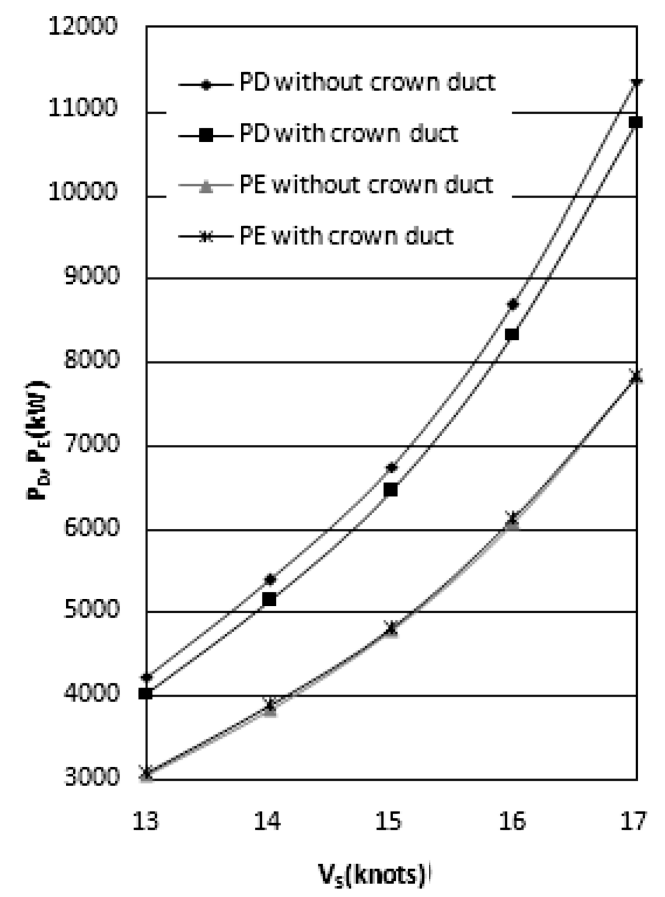

Fig. 5 Comparison of speed-power curve for the cases of bare hull and with crown duct at full load condition

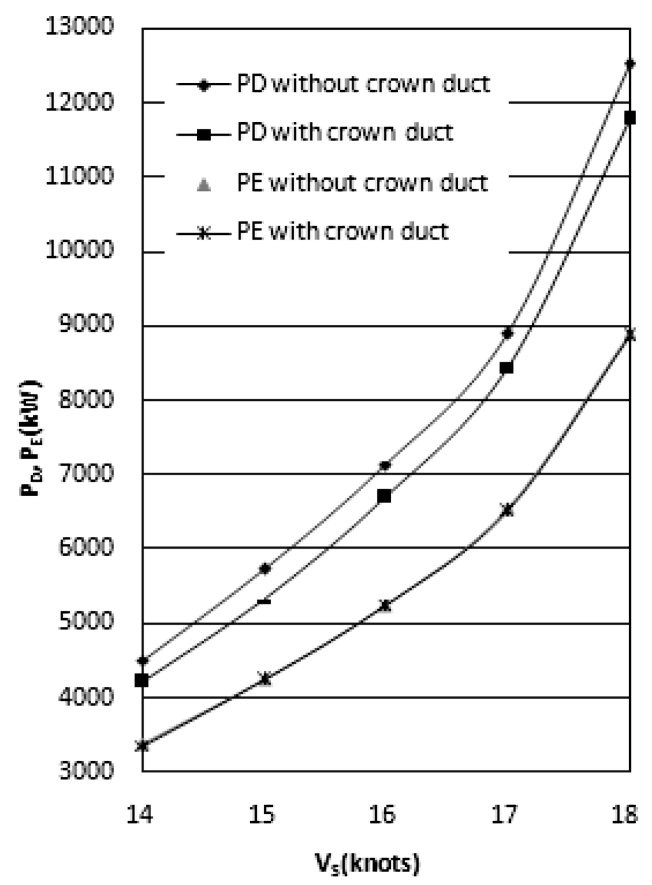

Fig. 6 Comparison of speed power curve for the cases of bare hull and with crown duct at ballast condition

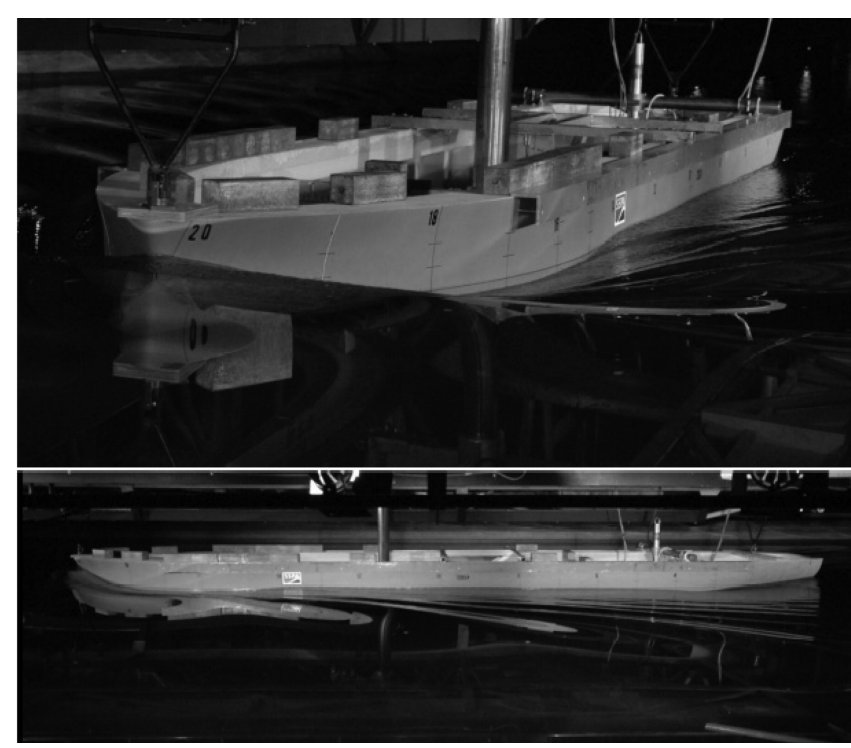

Fig. 7 Photos of self propulsion test in full load condition(at $V_{S}=15 \mathrm{knot}$ )

point of side fins than conventional pre-swirl stator, combination of semi-duct with minimum blades supposed to contribute to increase the wake(w) from 0.358 to 0.453 (increased 0.095 ) at full load condition and from 0.399 to 0.49 (increased 0.091) at ballast condition.

Fig. 4 is the photograph of model ship with "Crown Duct" which was tested in Towing tank, and Fig. 7 presents self propulsion test in full load condition(at design speed of 15.0 
knot).

\section{Conclusions}

Crown duct has been developed to recover the energy loss by improving propeller induced pre-rotating flow.

The model test result which is carried out in the towing tank shows that the wake factor(1-w) decreased up to considerable level.

Decreased wake factor supposed to be caused by reflecting flow generated from stator fins combination with semi-duct.

Propeller revolution decreased at same thrust condition due to the decreased wake factor, and propulsive efficiency increased.

Resultantly, efficiency gain attained $4.4 \%$ at full load condition and $6.9 \%$ at ballast condition.

\section{Aknowledgements}

This study was supported in part by research funds from Chosun University, 2011.

\section{References}

Asaumi. T., Ikeda. T., Tamashima. M., and Shinohara. H. (2006). “Effectiveness of an Energy Saving Device 'Friend
Fin', Conference Proceedings", The Japan Society of Naval Architecture and Ocean Engineering, Vol 3, pp 261-264.

Lare T. Gustafsson and Sopia Riisberg Jensen(2011). “Chosun 50K Tanker with Crown Duct". The Model Test Report of SSPA.

Lee, J.T., Kim, M.C., Suh, J.C., Kim, S.H. and Choi, J.K. (1992). “Development of a Preswirl Stator-Propeller System for Improvement of Propulsion Efficiency : a Symmetric Stator Propulsion System", Transactions of the Society of Naval Architects of Korea, Vol 29, No 4, pp 132-145.

Lee, J.T., Kim, M.C., Van, S.H., Kim, K.S. and Kim, H.C. (1994). "Development of a Preswirl Stator Propulsion System for a $300 \mathrm{~K}$ VLCC", Transactions of the Society of Naval Architects of Korea, Vol 31, No 1, pp 1-13.

Lee, K.J, and An, J.S.(2012). "Development of Complex Energy Saving Device", J of Ocean Engineering and Technology, Vol 26, No 3, pp 1-5.

Lee, K.J, An, J.S. Yang, S.H., Park, H.J. and Lim, Y.J.(2012). "Development of own Energy-Saving Device for SPP", The Research Report of Chosun University.

2012년 6월 14일 원고 접수

2012년 10월 18일 심사 완료

2012년 10월 25일 게재 확정 